\title{
Exigência de metionina + cistina digestíveis em suínos machos castrados de alto potencial genético na fase dos 60 aos $95 \mathrm{~kg}^{1}$
}

\author{
Fabrício de Almeida Santos ${ }^{2}$, Juarez Lopes Donzele ${ }^{3}$, Rita Flávia Miranda de Oliveira ${ }^{3}$, \\ Francisco Carlos de Oliveira Silva ${ }^{4}$, Márvio Lobão Teixeira de Abreu ${ }^{5}$, Alysson Saraiva ${ }^{6}$, \\ Paulo César Brustolini ${ }^{3}$
}

\footnotetext{
1 Projeto apoiado pela Ajinomoto Biolatina.

2 Doutorando DZO - UFV.

${ }^{3}$ DZO/UFV.

${ }^{4}$ EPAMIG - Viçosa - MG.

${ }^{5}$ DZO/UFPI.

${ }^{6}$ Mestrando em Zootecnia do DZO/UFV.
}

RESUMO - O experimento foi conduzido para determinação da exigência de metionina + cistina digestíveis de suínos de alto potencial genético para deposição de carne magra na fase dos 60 aos $95 \mathrm{~kg}$. Foram utilizados 70 suínos machos castrados, híbridos comerciais com mesmo padrão genético, com peso inicial de 60,00 $\pm 1,13 \mathrm{~kg}$, distribuídos em delineamento experimental de blocos ao acaso, com cinco níveis de metionina + cistina digestíveis $(0,440 ; 0,464 ; 0,488 ; 0,512$ e 0,536\%), correspondentes, respectivamente, às relações de 55,0; 58,0; 61,0; 64,0 e 67,0\% de metionina + cistina digestíveis:lisina digestível na dieta, sete repetições e dois animais por unidade experimental. As rações experimentais e a água foram fornecidas à vontade até o final do período experimental, quando os animais atingiram 94,95 \pm 0,50 kg. Os níveis de metionina + cistina digestíveis da ração influenciaram o ganho de peso, que aumentou de forma linear até o nível de 0,536\%, e a conversão alimentar e a quantidade de carne magra, que melhoraram de forma quadrática até os níveis estimados de 0,506 e 0,507\%, respectivamente. O consumo de metionina + cistina digestíveis aumentou de forma linear com o aumento dos níveis de metionina + cistina na dieta. Não houve efeito dos níveis de metionina + cistina sobre o consumo diário de ração, a espessura de toucinho, o rendimento de carcaça e a porcentagem de carne magra na carcaça. Suínos machos castrados de alto potencial genético para deposição

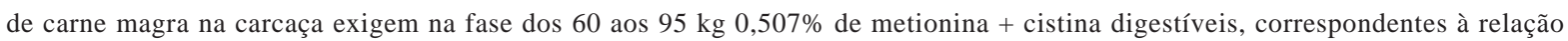
de metionina + cistina digestíveis:lisina digestível na ração de 63,0\%, para melhor conversão alimentar e maior quantidade de carne magra na carcaça.

Palavras-chave: aminoácidos sulfurados, carcaça, desempenho, nutrição, terminação

\section{Digestible methionine + cystine requeriment of high genetical potential barrows in the phase from 60 to $95 \mathrm{~kg}$}

\begin{abstract}
The experiment was conduced to determine the requirements of digestible methionine + cystine of barrows with high potential genetic for lean meat deposition from 60 to $95 \mathrm{~kg}$. Seventy hybrid commercial barrows with the same genetic pattern, with initial average weight of $60.00 \pm 1.13 \mathrm{~kg}$, were allotted to a randomized experimental blocks design with five digestible methionine and cystine levels $(0.440 ; 0.464 ; 0.488 ; 0.512$ and $0.536 \%$ ), corresponding, respectively, to 55.0; 58.0; 61.0, 64.0 and $67.0 \%$ of methionine and cystine: digestible lysine in the diet, seven replicates and two animals by experimental unity. The experimental diets and the water were ad libitum supplied until the end of experimental period when the animals reached an average weight of $94.95 \pm 0.50 \mathrm{~kg}$. The digestible methionine and cystine levels of ration influenced the daily weight gain that linearly increased up to the level of $0.536 \%$, and feed:gain and lean meat amount, which improved by a quadratic way up to the levels of 0.506 and $0.507 \%$, respectively. The digestible methionine and cystine intake linearly increased with the increase digestible methionine and cystine levels in the diet. There was no effect of the digestible methionine and cystine levels on feed intake, backfat thickness, carcass yield and percentage lean meat in the carcass. Barrows from 60 to $95 \mathrm{~kg}$ with high potential genetic for lean meat deposition in the carcass requiring $0.507 \%$ digestible methionine and cystine, corresponding to digestible methionine and cystine:digestible lysine in the ration of $63.0 \%$ for a better feed:gain and lean meat amount in the carcass.
\end{abstract}

Key Words: carcass, finishing, performance, nutrition, sulphurous amino acids 


\section{Introdução}

A tendência mundial de produção de suínos de alto potencial genético para deposição de carne magra e a elevação dos preços das fontes protéicas têm motivado nutricionistas a formularem rações que atendam adequadamente às exigências em aminoácidos desses animais. Consumos de aminoácidos abaixo ou acima das exigências biológicas do animal podem restringir a taxa e a eficiência de crescimento. Por outro lado, o nível adequado de aminoácidos na ração pode melhorar a eficiência alimentar, a taxa de crescimento e, conseqüentemente, aumentar o rendimento econômico da atividade suinícola.

Segundo o NRC, suínos de alto potencial genético apresentam ganho de carne magra igual ou superior a $350 \mathrm{~g} /$ dia. Esses animais apresentam alta demanda biológica de aminoácidos para mantença e crescimento. Entre esses aminoácidos, os sulfurados (metionina + cistina) destacam-se nas funções de manutenção por estarem envolvidos no turnover de tecidos intestinais e serem precursores de substâncias com várias funções biológicas.

A metionina exerce importante papel em diversas funções metabólicas, principalmente por ser o primer na síntese protéica. Na forma de S-adenosil metionina, a metionina é o mais importante doador de radicais metil no organismo e está envolvida na biossíntese de muitos componentes importantes para o crescimento e desenvolvimento dos suínos, como a creatina, a carnitina, as poliaminas, a epinefrina, a colina e a melatonina (Baker, 1991).

A cistina tem importante participação na estrutura de muitas proteínas, como a insulina e as imunoglobulinas, interligando cadeias polipeptídicas pela ponte dissulfeto (Baker, 1991). Além das funções biológicas, metionina + cistina tem sido considerado o segundo aminoácido limitante em rações práticas à base de milho e farelo de soja.

Existem diversas informações sobre as exigências de lisina para suínos de diferentes grupos genéticos, categorias e sexo. Entretanto, pesquisas sobre exigências de aminoácidos sulfurados para suínos na fase de terminação são escassas. Neste contexto, este trabalho foi realizado para determinar as exigências de metionina + cistina digestíveis e estabelecer sua relação com a lisina digestível para suínos machos castrados de alto potencial genético para deposição de carne magra na fase dos 60 aos $95 \mathrm{~kg}$.

\section{Material e Métodos}

O experimento foi conduzido na Granja de Suínos da Fazenda Experimental Vale do Piranga, pertencente à
EPAMIG, localizada no município de Oratórios, MG, no período de dezembro de 2003 a março de 2004.

Foram utilizados 70 suínos machos castrados de alto potencial genético para deposição de carne magra na carcaça, com peso inicial de 60,00 $\pm 1,13 \mathrm{~kg}$, distribuídos em delineamento experimental de blocos ao acaso, com cinco tratamentos $(0,440 ; 0,464 ; 0,488 ; 0,512 ; 0,536 \%$ de metionina + cistina digestíveis, correspondentes às relações de metionina + cistina digestíveis: lisina digestível de 55,0; 58,0; 61,0; 64,0 e 67,0\%, respectivamente), sete repetições e dois animais por unidade experimental. Na distribuição dos animais dentro de cada bloco, adotou-se como critério o peso inicial dos animais.

Os animais foram alojados em baias providas de comedouros semi-automáticos e bebedouros tipo chupeta, em galpão de alvenaria com piso de concreto e cobertura de telhas de amianto.

Durante todo o período experimental, foram registradas pela manhã as temperaturas de máxima e mínima do galpão.

As dietas experimentais, isoenergéticas e isolisínicas (Tabela 1), foram formuladas à base de milho, sorgo e farelo de soja e suplementadas com minerais e vitaminas, para atenderem às exigências dos animais, de acordo com recomendações de Rostagno et al. (2000), com exceção dos níveis de metionina + cistina. Foram avaliados cinco níveis de metionina + cistina digestíveis nas rações, obtidos a partir da inclusão de DL-metionina 99,0\% em substituição ao ácido glutâmico, em equivalente protéico. Verificou-se a relação aminoacídica entre a lisina e os demais aminoácidos essenciais, a fim de se assegurar que em todas as dietas nenhum outro aminoácido fosse limitante. Na avaliação das relações aminoacídicas das dietas, foram utilizadas as relações preconizadas por Rostagno et al. (2000) para proteína ideal para suínos na fase de terminação.

Durante o período experimental, os animais foram alimentados com as dietas experimentais e água à vontade. Realizou-se a pesagem das sobras de ração e, periodicamente, dos animais, para avaliação do ganho de peso, do consumo de ração (CDR) e da conversão alimentar (CA).

Ao final do período experimental, quando atingiram o peso final de $95,00 \pm 0,50 \mathrm{~kg}$, os animais foram mantidos em jejum por 18 horas e encaminhados para o abate, realizado no Frigorífico Industrial. Os animais foram insensibilizados por choque elétrico e sacrificados por sangramento. As carcaças foram depiladas com lançachamas e evisceradas. Posteriormente, foram avaliadas quanto ao rendimento de carne magra e à espessura de toucinho por meio de aparelho de tipificação de carcaça com pistola Henessy, conforme procedimentos adotados no frigorífico. 
Tabela 1 - Composições centesimal calculada e determinada das dietas experimentais

Table 1 - Percentage and nutritional compositions of the experimental diets

\begin{tabular}{|c|c|c|c|c|c|}
\hline \multirow[t]{2}{*}{ Item } & \multicolumn{5}{|c|}{$\begin{array}{c}\text { Nível de metionina + cistina digestível (\%) } \\
\text { Digestible methionine + cystine levels }\end{array}$} \\
\hline & 0,440 & 0,464 & 0,488 & 0,512 & 0,536 \\
\hline \multicolumn{6}{|l|}{$\begin{array}{l}\text { Ingrediente (\%) } \\
\text { Ingredient }\end{array}$} \\
\hline Milho (Corn) & 42,784 & 42,784 & 42,784 & 42,784 & 42,784 \\
\hline Farelo soja (Soybean meal) & 17,011 & 17,011 & 17,011 & 17,011 & 17,011 \\
\hline Sorgo baixo tanino (Low tanine sorghum) & 35,700 & 35,700 & 35,700 & 35,700 & 35,700 \\
\hline Óleo de soja (Soybean oil) & 1,600 & 1,600 & 1,600 & 1,600 & 1,600 \\
\hline L-Lys $\mathrm{HCl}$ & 0,300 & 0,300 & 0,300 & 0,300 & 0,300 \\
\hline L-Thr & 0,097 & 0,097 & 0,097 & 0,097 & 0,097 \\
\hline DL-Met & 0,000 & 0,025 & 0,049 & 0,074 & 0,098 \\
\hline$L-\operatorname{Trp}$ & 0,013 & 0,013 & 0,013 & 0,013 & 0,013 \\
\hline Fosfato bicálcico (Dicalcium phosphate) & 1,220 & 1,220 & 1,220 & 1,220 & 1,220 \\
\hline Calcário (Limestone) & 0,627 & 0,627 & 0,627 & 0,627 & 0,627 \\
\hline Premix mineral ${ }^{1}$ (Mineral mix) & 0,100 & 0,100 & 0,100 & 0,100 & 0,100 \\
\hline Premix vitamínica ${ }^{2}$ (Vitamin mix) & 0,075 & 0,075 & 0,075 & 0,075 & 0,075 \\
\hline Acido glutâmico (Glutamic acid) & 0,120 & 0,095 & 0,071 & 0,046 & 0,022 \\
\hline Sal (Salt) & 0,323 & 0,323 & 0,323 & 0,323 & 0,323 \\
\hline BHT & 0,010 & 0,010 & 0,010 & 0,010 & 0,010 \\
\hline Promotor crescimento (Growth promoter) & 0,020 & 0,020 & 0,020 & 0,020 & 0,020 \\
\hline \multicolumn{6}{|l|}{$\begin{array}{l}\text { Composição nutricional calculada }^{3} \text { e estimada } \\
\text { Calculated }^{3} \text { and estimated } \\
{ }^{4} \text { nutritional composition }\end{array}$} \\
\hline Proteína bruta (\%) (Crude protein) & 14,99 & 14,99 & 14,99 & 14,99 & 14,99 \\
\hline Energia digestível (kcal/kg) (Digestible energy) & 3.400 & 3.400 & 3.400 & 3.400 & 3.400 \\
\hline Lys total $(\%)$ & $0,894^{3} / 0,883^{4}$ & $0,894^{3} / 0,883^{4}$ & $0,894^{3} / 0,883^{4}$ & $0,894^{3} / 0,883^{4}$ & $0,894^{3} / 0,883^{4}$ \\
\hline Lys digestível (\%) (Digestible Lys) & $0,800^{3} / 0,790^{4}$ & $0,800^{3} / 0,790^{4}$ & $0,800^{3} / 0,790^{4}$ & $0,800^{3} / 0,790^{4}$ & $0,800^{3} / 0,790^{4}$ \\
\hline Met + Cys digestível (\%) (Digestible met + cys) & $0,440^{3} / 0,445^{4}$ & $0,464^{3} / 0,469^{4}$ & $0,488^{3} / 0,493^{4}$ & $0,512^{3} / 0,517^{4}$ & $0,536^{3} / 0,541^{4}$ \\
\hline Thr digestível (\%) (Digestible Thr) & $0,560^{3} / 0,544^{4}$ & $0,560^{3} / 0,544^{4}$ & $0,560^{3} / 0,544^{4}$ & $0,560^{3} / 0,544^{4}$ & $0,560^{3} / 0,544^{4}$ \\
\hline Trp digestível (\%) (Digestible Trp) & $0,160^{3} / 0,158^{4}$ & $0,160^{3} / 0,158^{4}$ & $0,160^{3} / 0,158^{4}$ & $0,160^{3} / 0,158^{4}$ & $0,160^{3} / 0,158^{4}$ \\
\hline $\mathrm{Ca}(\%)$ & 0,650 & 0,650 & 0,650 & 0,650 & 0,650 \\
\hline P disponível (\%) (Available P) & 0,320 & 0,320 & 0,320 & 0,320 & 0,320 \\
\hline $\mathrm{Na}(\%)$ & 0,160 & 0,160 & 0,160 & 0,160 & 0,160 \\
\hline
\end{tabular}

${ }^{1}$ Conteúdo/kg (Content/kg): Fe - 100 g; Cu - 10 g; Co - 1 g; Mn - 40 g; Zn - 100 g; excipiente q.s.p. - 1.000 g.

${ }^{2}$ Conteúdo/kg (Content/kg): vit. A - 6.000 .000 Ul; vit. $D_{3}-1.500 .000$ Ul; vit. E - 15.000 .000 Ul; vit. $B_{1}-1,35$ g; vit. $B_{2}-4$ g; vit. $B_{6}$. 2 g; ácido pantotênico (pantothenic acid) - 9,35 g; vit. $\mathrm{K}_{3}$ - 1,5 g; ácido nicotínico (nicotinic acid) - 20,0 g; vit. B12 - 20,0 g; ácido fólico (folic acid) - 0,6 g; biotina (biotine) - 0,08 g; I $1,5 \mathrm{~g}$; Se - 0,3 g; excipiente q. s. p. - $1.000 \mathrm{~g}$.

3 Composição calculada segundo Rostagno et al. (2000) (Composition calculated according Rostagno et al., 2000).

${ }^{4}$ Composição estimada a partir do aminograma realizado no Laboratório da Ajinomoto Biolatina e dos coeficientes de digestibilidade segundo Rostagno et al. (2005) (Composition estimated from Aminograma Laboratory Ajinomoto Biolatina and digestible coefficients according to Rostagno et al., 2005).

Foram avaliados o ganho de peso, o consumo diário de ração, a CA, a espessura de toucinho, a quantidade de carne magra, o peso da carcaça e a porcentagem de carne magra na carcaça.

As variáveis de desempenho e as características de carcaça foram analisadas pelo Sistema de Análises Estatísticas e Genéticas (SAEG) (UFV, 2000), versão 8.0, utilizando-se os procedimentos para análises de variância e de regressão.

\section{Resultados e Discussão}

As médias das temperaturas observadas nos termômetros de máxima e mínima foram $30,05 \pm 2,5^{\circ} \mathrm{C}$ e $21,13 \pm$ $1,5^{\circ} \mathrm{C}$, respectivamente, durante todo o período experimental. Considerando que a zona de conforto térmico para suínos nas fases de crescimento e terminação está compreendida, respectivamente, entre 18 e $23^{\circ} \mathrm{C}$ e 12 a $18^{\circ} \mathrm{C}$ (Perdomo, 1994), constatou-se, com base na variação de temperatura ocorrida na condução do experimento, que os animais experimentais foram submetidos a estresse por calor, o que não afetou seu desempenho produtivo.

Não houve efeito $(\mathrm{P}>0,10)$ dos níveis de metionina + cistina digestíveis sobre o consumo diário de ração (Tabela 2). Este resultado foi semelhante aos obtidos por Hahn \& Baker (1995) e Loughmiller et al. (1996b), em estudo com suínos em terminação, e por Vaz (2003) e Kiefer (2003), em experimento com suínos em crescimento em ambiente termoneutro, que também não observaram variação significativa no CDR com o aumento dos níveis de metionina + cistina digestíveis na dieta.

No entanto, Loughmiller et al. (1998), em três experimentos, e Knowles et al. (1998), em dois experimentos, 
Tabela 2 - Desempenho e consumo de metionina + cistina digestíveis de suínos machos castrados de alto potencial genético na fase dos 60 aos $95 \mathrm{~kg}$ alimentados com dietas com diferentes níveis de metionina + cistina digestíveis

Table 2 - Performance and digestible methionine + cystine intake of barrows with high genetic potential in the phase from 60 to $95 \mathrm{~kg}$ fed diets with different digestible methionine + cystine levels

\begin{tabular}{|c|c|c|c|c|c|c|}
\hline \multirow[t]{2}{*}{ Item } & \multicolumn{5}{|c|}{$\begin{array}{c}\text { Nível de metionina + cistina digestível (\%) } \\
\text { Digestible methionine + cystine level }\end{array}$} & \multirow[t]{2}{*}{$\mathrm{CV} \%$} \\
\hline & 0,440 & 0,464 & 0,488 & 0,512 & 0,536 & \\
\hline Consumo diário de ração (g) (Daily diet intake) & 2.863 & 2.750 & 2.790 & 2.868 & 2.834 & 6,84 \\
\hline Ganho de peso diário (g) ${ }^{1}$ (Daily weight gain) & 1.056 & 1.057 & 1.108 & 1.189 & 1.109 & 7,27 \\
\hline Conversão alimentar (g)/(g) ${ }^{2}$ (Feed:gain ratio) & 2,71 & 2,60 & 2,52 & 2,41 & 2,56 & 4,40 \\
\hline Consumo diário met + cis dig $(\mathrm{g})^{3}($ Dig met + cys intake $)$ & 12,60 & 12,76 & 13,62 & 14,68 & 15,19 & 7,07 \\
\hline
\end{tabular}

1 e 3 Efeito linear, $\mathrm{P}<0,05$ e $\mathrm{P}<0,01$, respectivamente.

2 Efeito quadrático $(P<0,01)$.

1 and 3 Linear effect, $P<0.05$ and $P<0.01$, respectively.

2 Quadratic effect $(P<0.01)$.

todos com suínos em terminação, constataram influência significativa dos níveis dos aminoácidos sulfurados da dieta sobre o consumo voluntário da dieta dos animais. A diferença no CDR entre os trabalhos pode estar relacionada, entre outros fatores, às diferenças nos níveis dos aminoácidos sulfurados avaliados e suas relações com a lisina, que corresponderam a valores abaixo de $55 \%$ e/ou acima de $67 \%$, que constituíram os valores limites avaliados neste estudo.

Os níveis de metionina + cistina digestíveis influenciaram $(\mathrm{P}<0,05)$ o ganho de peso diário (GPD), que aumentou de forma linear segundo a equação: $\hat{Y}=622,028+$ $988,195 X\left(r^{2}=0,48\right)$. Apesar do aumento linear no GPD dos animais, verificou-se redução de $6,7 \%$ no valor absoluto do GPD (1189 x 1109g) entre os dois maiores níveis de metionina + cistina estudados $(0,512 \times 0,536 \%)$. Essa resposta indica que o nível de metionina + cistina digestíveis de 0,512\%, correspondente a relação com a lisina digestível de 64,0\%, foi suficiente para atender à demanda dos animais para maior GPD.

A resposta de CDR dos animais aos níveis dos aminoácidos sulfurados obtida neste trabalho confirma o relato de Edmonds \& Baker (1987) de que suínos toleram excesso de metionina sem apresentarem alteração significativa no consumo de alimento.

Efeito positivo do aumento do nível de metionina + cistina da ração sobre o GPD de suínos em terminação também foi encontrado por Chung et al. (1989), no entanto, outros autores (Hahn \& Baker, 1995; Knowles et al.1998; Grandhi \& Nyachoti, 2002) não encontraram efeito dos níveis de metionina + cistina sobre o GPD de suínos na fase de terminação. A divergência nos resultados entre os estudos pode ser justificada, em parte, pelo nível de lisina utilizado nas dietas experimentais.

Loughmiller et al. (1996a), avaliando a influência de níveis de metionina + cistina das dietas correspondentes às relações de 60,0; 65,0 e 70,0\% com a lisina, utilizaram dois níveis de lisina (0,55 e 0,70\%) e verificaram que o padrão de resposta de GPD dos animais aos níveis de metionina + cistina das dietas variou de acordo com o nível de lisina utilizado. Embora os melhores resultados de GPD tenham sido obtidos nos níveis de aminoácidos sulfurados correspondentes às relações de 60,0 e $65,0 \%$, quando se utilizou o nível de $0,55 \%$ de lisina, essas respostas ocorreram nos níveis de metionina + cistina correspondentes às relações de 65,0 e 70,0\%, quando o nível de lisina correspondeu a $0,70 \%$.

Os resultados obtidos por Loughmiller et al. (1998) para a influência dos níveis de metionina + cistina das rações correspondentes às relações de 63,0; 70,0 e 77,0\% com a lisina digestível utilizando dois níveis de lisina $(0,44 \%$ e $0,56 \%)$ confirmaram que a resposta de ganho de peso dos suínos aos níveis de metionina + cistina das rações pode variar de acordo com o nível de lisina da ração experimental. Neste trabalho, observou-se aumento no GPD quando as relações aumentaram de 63 para $70 \%$ na dieta, com $0,56 \%$ de lisina digestível, enquanto, nas dietas com 0,44\% de lisina digestível, houve redução no ganho de peso com o aumento das relações de metionina + cistina digestível:lisina digestível nas rações.

A conversão alimentar dos animais foi influenciada pelas dietas e diminuiu $(\mathrm{P}<0,05)$ de forma quadrática até 0 nível estimado de $0,506 \%$ de metionina + cistina digestíveis na dieta, correspondente a uma relação de $63,0 \%$ com a lisina digestível (Figura 1).

De forma semelhante, Chung et al. (1989) e Hahn \& Baker (1995) verificaram aumento na eficiência de utilização do alimento para ganho de peso pelos suínos em terminação, em razão da elevação dos níveis de metionina + cistina digestíveis na dieta.

No entanto, os resultados de CA obtidos neste estudo diferem dos encontrados por Loughmiller et al. (1996a), que 


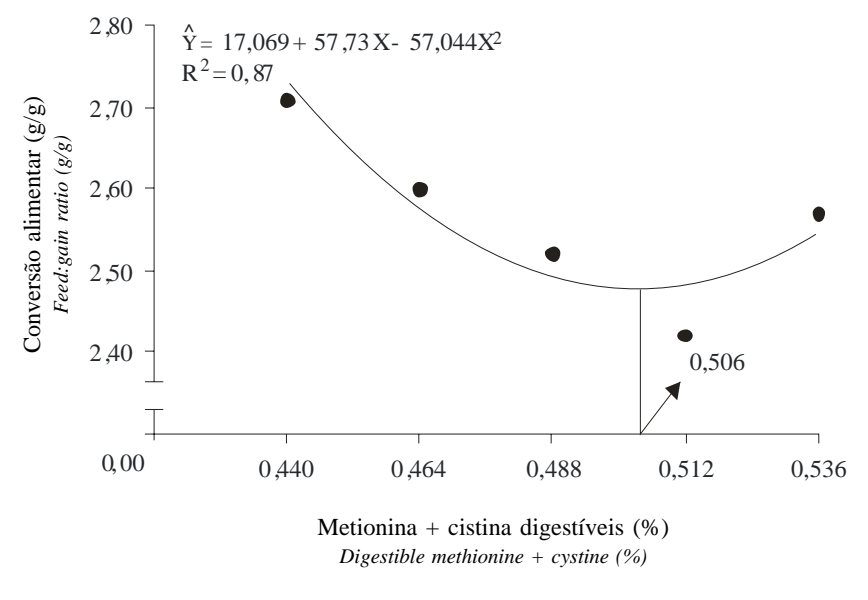

Figura 1 - Conversão alimentar de suínos machos castrados de alto potencial genético na fase dos 60 aos $95 \mathrm{~kg}$ alimentados com dietas com diferentes níveis de metionina + cistina digestíveis.

Figure 1 - Feed:gain ratio of barrows with high potential in the phase from 60 to $95 \mathrm{~kg}$ fed diets with different digestible methionine + cystine levels.

não observaram efeito dos níveis de metionina + cistina sobre a conversão alimentar de suínos em terminação.

A variação dos resultados de conversão alimentar entre esses trabalhos pode ser atribuída a fatores como genética, sexo dos animais e composição das rações experimentais.

Resultados obtidos por Loughmiller et al. (1998) em dois experimentos com suínos em terminação evidenciaram diferentes respostas de CA aos níveis de metionina + cistina avaliados. Quando os níveis desses aminoácidos corresponderam às relações de 63,0; 70,0 e 77,0\% com a lisina em um experimento, a CA dos animais não variou entre as dietas. No entanto, quando estas relações variaram de 45,0 a 65,0\% em outro experimento, a CA melhorou de forma linear.

Knowles et al. (1998), avaliando o desempenho de suínos machos castrados e fêmeas em terminação alimentados com dietas com diferentes relações de metionina + cistina total:lisina total e relações variaram de 50,0 a 70,0\%, verificaram efeito significativo dos níveis de metionina + cistina nas dietas.

O consumo de metionina + cistina aumentou $(\mathrm{P}<0,01)$ de forma linear à medida que se elevou o nível desses aminoácidos na ração, $\hat{\mathrm{Y}}=-0,701+29,658 \mathrm{X}\left(\mathrm{r}^{2}=0,96\right)$. Aumento linear no consumo de aminoácidos sulfurados pelos suínos de acordo com suas concentrações na dieta também foi relatado por Loughmiller et al. (1996a, 1998).

Como o consumo de ração não variou significativamente entre os níveis de metionina + cistina digestíveis avaliados, o consumo desses aminoácidos aumentou diretamente em razão do crescente nível de inclusão de metionina na dieta.

Os níveis de metionina + cistina digestíveis na dieta não tiveram efeito $(\mathrm{P}>0,05)$ sobre a espessura de toucinho no ponto $\mathrm{P}_{2}\left(\mathrm{ETP}_{2}\right)$, o peso da carcaça (PC) e a porcentagem de carne magra (PCM) na carcaça (Tabela 3). Esses resultados são semelhantes aos obtidos por Lenis et al. (1990), Loughmiller et al. (1996 a,b; 1998) e Grandhi \& Nyacothi (2002), que, em suínos em terminação, também não constataram variação nessas características de carcaça decorrente do aumento dos níveis de metionina + cistina na dieta.

O valor médio obtido neste estudo para a porcentagem de carne magra na carcaça dos animais (57,37\%), que corresponde a uma deposição de carne magra diária, calculada segundo o NRC (1998), de 377 g, caracteriza os animais como de alto potencial genético.

De forma semelhante, Knowles et al. (1998) avaliaram diferentes relações metionina + cistina total com a lisina total (50,0; 55,0; 60,0; 65,0; 70,0\%) em rações com 0,55 e $0,65 \%$ de lisina para suínos em terminação e não verificaram efeito das dietas sobre essas características de carcaça, independentemente do nível de lisina utilizado. Todavia, em outro experimento conduzido com fêmeas suínas em terminação (74 a $110 \mathrm{~kg}$ ), esses autores verificaram aumento linear na porcentagem de carne livre de gordura na carcaça,

Tabela 3 - Características de carcaça de suínos machos castrados de alto potencial genético na fase dos 60 aos $95 \mathrm{~kg}$ alimentados com dietas com diferentes níveis de metionina + cistina digestíveis

Table 3 - Carcass characteristics of barrows with high genetic potential in the phase from 60 to $95 \mathrm{~kg}$ fed diets with different digestible methionine + cystine levels

\begin{tabular}{|c|c|c|c|c|c|c|}
\hline \multirow[t]{2}{*}{ Item } & \multicolumn{5}{|c|}{$\begin{array}{c}\text { Nível de metionina + cistina digestível (\%) } \\
\text { Digestible methionine + cystine level }\end{array}$} & \multirow[t]{2}{*}{$\mathrm{CV} \%$} \\
\hline & 0,440 & 0,464 & 0,488 & 0,512 & 0,536 & \\
\hline Espessura de toucinho (mm) (Backfat thickness) & 11,97 & 10,80 & 11,84 & 11,56 & 11,76 & 18,76 \\
\hline Rendimento de carne magra $(\mathrm{kg})^{1}$ (Lean meat yield) & 35,72 & 37,73 & 38,48 & 39,40 & 38,30 & 7,53 \\
\hline Peso da carcaça (kg) (Carcass weight) & 64,77 & 64,48 & 67,30 & 67,51 & 66,44 & 6,10 \\
\hline Carne magra (\%) (Lean meat percentage) & 55,15 & 58,51 & 57,18 & 58,36 & 57,65 & 2,92 \\
\hline
\end{tabular}

${ }^{1}$ Efeito quadrático $(P<0,05)$.

${ }^{1}$ Quadratic effect $(P<0.05)$. 


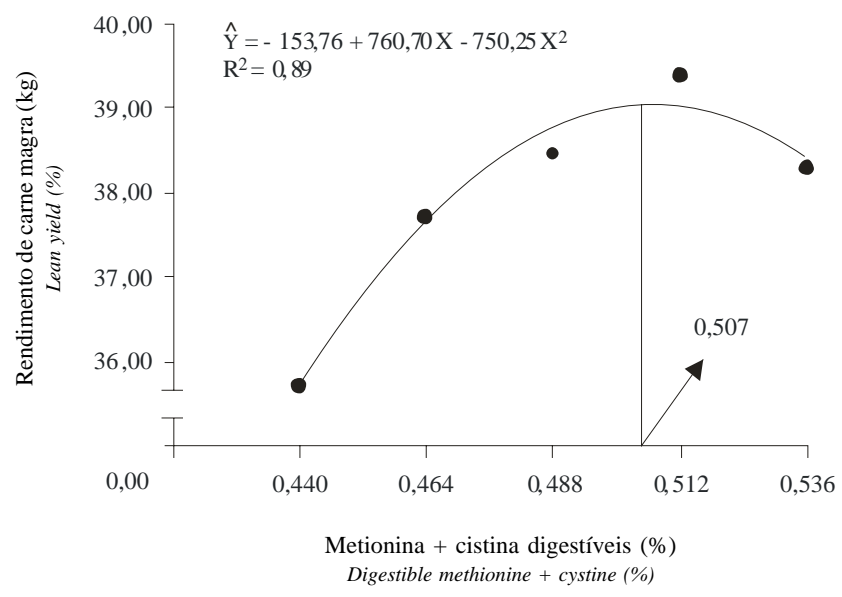

Figura 2 - Rendimento de carne magra de suínos machos castrados de alto potencial genético na fase dos 60 aos $95 \mathrm{~kg}$ alimentados com dietas com diferentes níveis de metionina + cistina digestíveis.

Figure 2 - Lean yield of barrows with high genetic potential in the phase from 60 to $95 \mathrm{~kg}$ fed diets with different digestible methionine + cystine levels.

atribuído ao aumento gradual de lisina na relação metionina + cistina:lisina da dieta.

Os níveis de metionina + cistina digestíveis das rações influenciaram $(\mathrm{P}<0,05)$ de forma quadrática o rendimento de carne magra (RCM) na carcaça, que aumentou até o nível estimado de $0,507 \%$, correspondente a uma relação com a lisina digestível de 63,0\% (Figura 2). Efeito positivo dos níveis de metionina + cistina digestíveis sobre RCM também foi observado por Kiefer (2003), em suínos em crescimento (30 a $60 \mathrm{~kg}$ ) mantidos em ambiente termoneutro, e por Knowles et al. (1998), que verificaram aumento linear na RCM de suínos em terminação à medida que se elevou a relação metionina + cistina:lisina de 35 para $65 \%$.

Com os resultados de RCM obtidos neste estudo, evidenciou-se que, além do ganho de peso, os níveis de metionina + cistina digestíveis também influenciaram a composição do ganho favorecendo a deposição de carne na carcaça, o que, em parte, justifica os resultados de CA dos animais.

A associação entre a melhora no RCM e na CA está relacionada ao fato de que a deposição de $1 \mathrm{~g}$ de proteína na carcaça agrega maior quantidade de água $(3,1 \mathrm{~g})$ se comparada à deposição de $1 \mathrm{~g}$ de gordura (Krick et al. 1992).

Neste estudo, o nível de metionina + cistina digestível de $0,507 \%$, correspondente à relação de $63,0 \%$ com a lisina digestível, atendeu às exigências dos animais para melhor desempenho e características de carcaça. Essa relação (63,0\%), apesar de próxima à de 65,0\%, proposta por Fuller et al. (1989), encontra-se acima da preconizada pelo NRC
(1998), de 59,0\%, e abaixo da recomendada por Rostagno et al. (2000), de 70,0\%.

Entre os fatores que podem ter contribuído para a diferença de resultados entre os trabalhos, destacam-se os diferentes critérios de resposta avaliados e o status sanitário dos animais.

Knowles et al. (1998), em pesquisa com fêmeas suínas em terminação, estimaram que a relação metionina + cistina:lisina total exigida pelos animais é de $40,0 \%$ para melhor resposta de ganho de peso, a 57,0\% para melhor relação carne:gordura e a 65,0\% para minimizar a deposição de gordura na carcaça.

A metionina tem sido apontada como um dos principais aminoácidos com importantes funções metabólicas de mantença por ser precursora de imunoglobulinas e um primer na síntese protéica. Além disso, segundo Obled (2003), a metionina é precursora da cisteína, aminoácido que, durante processos inflamatórios, é utilizado para síntese de componentes antioxidantes importantes como a glutationa. Neste estudo, é possível que os animais tenham sofrido baixo desafio sanitário, o que justificaria valores de exigências de metionina + cistina inferiores aos observados em outros estudos.

\section{Conclusões}

A exigência de metionina + cistina digestíveis de suínos machos castrados de alto potencial genético na fase dos 60 aos $95 \mathrm{~kg}$ é de 0,507\%, que corresponde a uma relação metionina + cistina digestíveis:lisina digestível de $63,0 \%$.

\section{Literatura Citada}

BAKER, D.H. Partitioning of nutrients for growth and other metabolic functions. Poultry Science, v.70, n.8, p.1797-1805, 1991.

CHUNG, T.K.; IZQUIERDO, O.A.; HASHIMOTO, K. Methionine requirement of the finishing pigs. Journal of Animal Science, v.67, p.2677-2683, 1989.

EDMONDS, M.S.; GONYOU, H.W.; BAKER, D.H. Effect of excess levels of excess methionine, tryptofhan, arginine, lysine or threonine on growth and dietary choice in the pig. Journal of Animal Science, v.65, n.1, p.179-185, 1987.

FULLER, M.F.; McWILLIAM, R.; WANG, T.C. The optimum dietary amino acid pattern for growing pigs. 2. Requirements for maintenance and for tissue protein accretion. British Journal of Nutrition, v.62, n.2, p.255-267,1989.

GRANDHI, R.R.; NYACHOTI, C.M. Effect of true ileal digestible dietary methionine to lysine ratios on growth performance and carcass merit of boards, gilts and barrows selected for low backfat. Canadian Journal of Animal Science, v.82, n.3, p.399-407, 2002.

HAHN, J.D.; BAKER, DH. Optimum ratio to lysine of threonine, tryptophan and sulfur amino acids for finishing swine. Journal of Animal Science, v.73, n.2, p.482-489, 1995.

KIEFER, C. Exigência de aminoácidos sulfurados digestíveis para suínos mantidos em diferentes ambientes térmicos 
dos 30 aos 60 kg. Viçosa, MG: Universidade Federal de Viçosa, 2003. 44p. Dissertação (Mestrado em Zootecnia) - Universidade Federal de Viçosa, 2003.

KNOWLES, T.A.; SOUTHERN, L.L.; BINDER, T.D. Ratio of total sulfur amino acids to lysine for finishing pigs. Journal of Animal Science, v.76, n.4, p.1081-1090, 1998.

KRICK, B.J.; BOYD, R.D. Influence of genotype and sex on the response of growing pigs to recombinant porcine sonatotropin. Journal of Animal Science, v.70, n.10, p. 3024, 1992.

LENIS, N.P.; van DIEPEN, J.T.H.M.; GOEDHART, P.W. Amino acid requirements of pigs. 1. Requirement for methionine + cystine, threonine and tryptophan of fast-growing boards and gilts, fed ad libitum. Netherlands Journal of Agricultural Science, v.38, p.577-595, 1990.

LOUGHMILLER, J.A.; GOODBAND, R.D.; TOKACH, M.D. et al. Evaluation of the sulfur amino acid requirement of finishing pigs. Swine Day, p.130-132, 1996a.

LOUGHMILLER, J.A.; TOKACH, M.D.; GOODBAND, R.D. et al. Dietary total sulfur aminoacid requirement for optimal growth performance and carcass characteristics in finishing gilts. Swine Day, p.133-135, 1996b.

LOUGHMILLER, J.A.; NELSSEN, J.L.; GOODBAND, R.D. et al. Influence of dietary total sulfur amino acid and methionine on growth performance and carcass characteristics in finishing gilts. Journal of Animal Science, v.76, n.8, p. 2129-2137, 1998

NATIONAL RESEARCH COUNCIL - NRC. Nutrient requirements of swine. 10.ed. Washington, D.C.: National Academic Science, 1998. 189p.

OBLED, C. Necessidades de aminoácidos em estados inflamatórios. In: CURSO DE ESPECIALIZAÇÕES FEDNA, 19., 2003, Madri. Proceedings... Madrid: Uniti de Nutrition et Metabolisme Proteique, INRA, 2003. (CD-ROM).

PERDOMO, C.C. Conforto ambiental e produtividade de suínos. In: SIMPÓSIO LATINO AMERICANO DE NUTRIÇÃO DE SUÍNOS, 1994, São Paulo. Anais... São Paulo: Colégio Brasileiro de Nutrição Animal, 1994. p.19-26.
ROSTAGNO, H.S.; ALBINO, L.F.T.; DONZELE, J.L. et al. Composição de alimentos e exigências nutricionais de aves e suínos: tabelas brasileiras. Viçosa, MG: Universidade Federal de Viçosa, 2000. 141p.

ROSTAGNO, H.S.; ALBINO, L.F.T.; DONZELE, J.L.; et al. Composição de alimentos e exigências nutricionais de aves e suínos: tabelas brasileiras. Viçosa, MG: Universidade Federal de Viçosa, 2005. 186p.

SILVA, M.A.; ALBINO, L.F.T.; ROSTAGNO, H.S. Exigências nutricionais em metionina + cistina e de proteína bruta, para frangos de corte, em função do nível de proteína bruta da ração. Revista Brasileira de Zootecnia, v.27, n.2, p.357-363, 1997.

SOLBERG, J.; BUTTERY, P.J.; BOORMAN, K.N. Effect of moderate methionine deficiency on food, protein and energy utilization in the chick. British Poultry Science, v.12, n.3, p.297-304, 1971.

TUITOEK, K.; YOUNG, L.G.; DE LANGE, C.F.M. The effect of reducing excess dietary amino acids on growing-finishing pig: an evaluation of the ideal protein concept. Journal of Animal Science, v.75, n.6, p.1575-1583, 1997.

UNIVERSIDADE FEDERAL DE VIÇOSA - UFV. Manual de utilização do programa (Sistemas de Análises Estatísticas e Genéticas - SAEG). (versão 8.0). Viçosa, MG: Universidade Federal de Viçosa, 2000. 150p.

VAZ, R.G.M.V. Exigências de aminoácidos sulfurados para suínos machos castrados mantidos em diferentes ambientes térmicos dos 15 aos $30 \mathrm{~kg}$. Viçosa, MG: Universidade Federal de Viçosa, 2003. 39p. Dissertação (Mestrado em Zootecnia) - Universidade Federal de Viçosa, 2003. 